Mongolian Geoscientist

Original article

\title{
UAV and terrestrial laser scanner data processing for large scale topographic mapping
}

\author{
Ganbold Ulziisaikhan*, Dash Oyuntsetseg
}

Department of Geodesy, School of Geology and Mining, Mongolian University of Science and Technology, Ulaanbaatar 14191, Mongolia

*Corresponding author.Email: ulziis@must.edu.mn

\section{ARTICLE INFO}

Article history:

Received 01 March, 2020

Accepted 20 May, 2020

\begin{abstract}
Integrating spatial data from different sources results in visualization, which is the last step in the process of digital basic topographic map creation. Digital elevation model and visualization will used for geomorphological mapping, geospatial database, urban planning and etc. Large scale topographic mapping in the world countries is really a prominent challenge in geospatial industries today. The purpose of this work is to integrate laser scanner data with the ones generated by aerial photogrammetry from UAV, to produce detailed maps that can used by geodetic engineers to optimize their analysis. In addition, terrestrial - based LiDAR scans and UAV photogrammetric data were collected in Sharga hill in the north zone of Mongolia. In this paper, different measurement technology and processing software systems combined for topographic mapping in the data processing scheme. UTM (Universal Transverse Mercator) projected coordinate system calculated in WGS84 reference ellipsoid. Feature compilation involving terrestrial laser scanner data and UAV data will integrated to offer Digital Elevation Models (DEM) as the main interest of the topographic mapping activity. Used UAV generate high-resolution orthomosaics and detailed 3D models of areas where no data, are available. That result issued to create topographic maps with a scale of 1:1000 of geodetic measurements. Preliminary results indicate that discontinuity data collection from UAV closely matches the data collected using laser scanner.
\end{abstract}

Keywords: Digital elevation model (DEM), map projection, data analysis, ground control points (GCP)

\section{INTRODUCTION}

Geospatial information nowadays has turned into a primary need in human lives. This characteristic leads to a massive development of geospatial industries in parallel with the invention of new technologies in an open and attractive worldwide market. Heavy competition from different platforms, sensors, and techniques is coming up as a logical result of a geospatial demand explosion around the globe. Topographical research has required a new surveying system with new techniques and technologies based on geographic information system, remote sensing, modern surveying techniques, combined with traditional methods. Therefore, it has required an analyzed DEM and

(C) The Author(s). 2020 Open access This article is distributed under the terms of the Creative Commons Attribution 4.0 International License (https://creativecommons.org/licenses/by/4.0/), which permits unrestricted use, distribution, and reproduction in any medium, provided you give appropriate credit to the original author(s) and source, provide a link to the Creative Commons license, and indicate if changes were made. 
3D digital images, such as hillshade, aspect, slope etc. Terrestrial laser scanning (TLS) is a well-known remote-sensing technique for acquisition of accurate information on the physical surface of an observed object, leading to a high density point cloud that can be used in turn to create accurate digital models. This technique is currently used in several disciplines, e.g. geology and geomorphology, architecture and civil engineering, and mobile mapping (Vosselman and Maas 2010). Lightweight unmanned aerial vehicles (UAVs) are now widely used in geological and architectural survey, thanks to the availability of relatively stable quad-rotor helicopter systems. The fact that Structure from Motion (SfM) requires no more than a camera makes such a technique particularly suitable for UAV-based surveys (Niethammer et al. 2012, MartínezEspejo Zaragoza et al., 2017).

Different sources were used for the purpose of creating basic topographic maps at 1:1000 scales. After selecting a dataset from analyzed DEM and data from other sources are processed and transformed it is necessary to perform the procedure of partial or complete data generalization and to define possible methods for geomorphology mapping. Classification of morphology and morphogenetic features are based on the field study measurements, high accurate digital elevation model (DEM), large scale topographic map and targeted to use mapping methodology for choosing territory (Bayanjargal and Nyamkhuu 2017). Digital Elevation Model (DEM) is an important topographic product and essential demand for many applications (Uysal et al., 2015). This paper will document the components of each of these elements as well as how the DEM representation topographic map can be used.

\section{RESEARCH BACKGROUND}

Large scale topographic mapping of Mongolia has been conducted twice since 2003, the first of which is the 21 provinces, 329 sub provinces and a province of the cadastral mapping and land registry project, which were implemented on a concessional loan from the Asian Development Bank (ADB) in 2003. Topographic mapping at the 1:1000 scale was performed-between 2013 and 2017, the topographic mapping was done in 21 provinces, 330 sub provinces and 45 settlements in the updating clarification of topographic map at 1: 1000 scale. It depends on the accuracy of the geodetic surveying, an equipment and the method.

Topographical maps are essential because they contain basic geospatial features including earth surface terrain information with respect to its proper geometrical accuracies. Some recently upcoming alternative technologies for geospatial data production give a high resolution solution to the generation of orthophotos and digital elevation models (DEM) (Tampubolon and Reinhardt, 2014).

UAV appears as a breakthrough which can combine interesting high resolution data acquisition with relatively simple and cheap platforms in comparison with conventional airborne campaigns (Neitzel and Klonowski, 2011). By flying at low altitude, the captured UAV photos and laser scanner data provide the geospatial objects with high details and full color.

\section{SURVEY AREA}

Chosen territory is located in Ulziit Mountain in Manlai sub province, covering a subject area of 62.6 hectares, in the Umnugobi province, Gobi Desert (see Fig. 1). It is surrounded by natural scenery of dependent mountain ranges between steppe such as Zagiin Us, Bulan Delger, and Amgalan Gobi. Survey area is destined in 470 $\mathrm{km}$ from Ulaanbaatar, $230 \mathrm{~km}$ east of the Dalanzadgad, bordering Mandakh sub province of Dundgovi province. The elevation of the subject areas varies in the range between 1000 $\mathrm{m}$ and $1300 \mathrm{~m}$, with a mean altitude of $1154 \mathrm{~m}$. It makes sense to use GCP data from different types for data production and validation.

\section{CALCULATING MAP PROJECTION}

For UTM zones, a correction of 0.9996 is applied so that the scale factor ranges from 0.9996 to 1.0010. Therefore, distances computed from UTM coordinates within a particular zone will be correct to within 0.1 percent. The UTM is also constrained to a window of latitude from $80^{\circ} \mathrm{S}$ to $84^{\circ} \mathrm{N}$. UTM 




Fig. 1. Satellite image of the Sharga hill survey area on the Google Earth Map, 2019

coordinates do not have to be computed from these 60 zones. It is commonly used topographic map with many various scales. Calculation of UTM projection is different theories, formulas than other map projection. One of these is projected coordinate system, that has difference a scale factor from TM map projection. Ellipsoids are defined by two parameters: the semi-major axis, and flattening ratio. The semi-major axis runs from the center of the ellipsoid of the equator and the flattening parameter defines the ratio of the difference between the semi-major and semi-minor axes. From these two parameters (Manchuk, 2009), other constants are derived, including the semiminor axis and the eccentricity. Calculation of
UTM coordinates planimetric data for topographic map scale with 1:1000, values are shown in following Table 1.

It is baseline data, that connected result of geodetic measurement. Defined distortion of distance (Eq.1) and area scale factor (Eq.2) formulas are as follows.

$$
\begin{aligned}
& m=\arcsin (\sin (l-m) \cdot \cos (j)) \\
& p=0.9992 \cdot\left(1+\cos (j)^{2} \cdot(l-m)^{2}\right)
\end{aligned}
$$

Numerical calculations with the WGS 84 ellipsoid give the value as $\mathrm{m}=1.001421$, $\mathrm{p}=1.002258$. AutoCAD MAP software was used to point data as XYZ Grid, Intersection of XY

Table 1. Datum and Parameters of UTM projected coordinate system

\begin{tabular}{|c|r|r|}
\hline \multirow{4}{*}{ Datum } & \multicolumn{2}{|c|}{ WGS 84 } \\
& $a$ (semi-major axis) & 6378137 \\
\cline { 2 - 3 } & $b$ (semi-major axis) & 6356752.314 \\
\cline { 2 - 3 } & farameters & 0.003352811 \\
\cline { 2 - 3 } & $1 / f$ (inverse flattening) & 298.2572236 \\
\cline { 2 - 3 } & r (radius) & 6367435.68 \\
\cline { 2 - 3 } & $k_{0}$ (scale factor) & 0.9996 \\
\cline { 2 - 3 } & $e$ (eccentricity) & 0.081819191 \\
\cline { 2 - 3 } & $e^{2}$ & 0.006739497 \\
\hline
\end{tabular}


locating procedure has been applied with a $10^{-5}$ m snapping accuracy.

\section{SURVEYING AND DATA PROCESSING}

This paper will mainly concentrate on the analysis of orthophotos and DEMs. The various object types are stored in different layers and can be displayed individually or in combination. The storage in databases allows also an analysis of the map data. The generation and updating of such geographic information systems (GIS) is a major task of mapping organizations. Details on the assessed accuracy, the time of acquisition, and many other information are stored in metadata. Topographic maps are always georeferenced and may also contain elevations. The separation into a planimetric (2D) map and an accompanying DEM seems to be a trend in mapping including updating (Joachim, 2017) Mapping methodologies are depending on the base map, additional clarification field works using equipment and so on. Topographic mapping by an unmanned aerial vehicle (UAV), commonly known as a drone, is an aircraft without a human pilot aboard. Once the camera is properly configured according to the scene, a flight plan must be designed and carried out. Firstly, a study of the terrain elements must be performed in order to assert that the images will contain enough features (Ruiz et al., 2013). Image processing is done via specialized software. The quality of used digital camera and lens is very important for image processing. Optical errors can be corrected by camera calibration.

The AGISOFT PhotoScan software can perform the calibration automatically when processing images (Blistan et al., 2016). The most common method to determine elements of external orientation is the use of ground control points with known coordinates determined by geodetic methods in the field. The results of the processing of the aerial images in specialized software are typically orthophoto map, point cloud or DEM. Selected technical parameters of UAV are given in Table 2 .

Ideally, the image overlaps should be 60-70 percent (Xing et al., 2010). The vertical overlays are 80 percent and horizontal overlays are 60 percent. Major $(5 \mathrm{~m})$ and minor $(1 \mathrm{~m})$ contour lines of UAV data acquisition and processing is displayed in Fig. 2.

The geometric survey was operated with horizontal field-of-view $\left(360^{\circ}\right)$ Trimble FARO HD x130. The laser scanner is a $0.6-130 \mathrm{~m}$ reflection, a dynamic frame with a high

Table 2. The selected technical parameters of UAV Phantom 4 Pro

\begin{tabular}{|c|c|}
\hline \multicolumn{2}{|l|}{ Aircraft } \\
\hline Weight & $1388 \mathrm{~g}$ \\
\hline Max Ascent / Descent Speed & S-mode: $6 \mathrm{~m} / \mathrm{s}, \mathrm{P}$-mode: $5 \mathrm{~m} / \mathrm{s}$ \\
\hline Max Flight Speed & $\begin{array}{l}\text { S-mode: } 45 \mathrm{mph}(72 \mathrm{kph}) \\
\text { A-mode: } 36 \mathrm{mph}(58 \mathrm{kph}) \\
\text { P-mode: } 31 \mathrm{mph}(50 \mathrm{kph})\end{array}$ \\
\hline Operating Temperature Range & $32^{\circ}$ to $104^{\circ} \mathrm{F}\left(0^{\circ}\right.$ to $\left.40^{\circ} \mathrm{C}\right)$ \\
\hline Satellite Positioning Systems & GPS/GLONASS \\
\hline \multicolumn{2}{|l|}{ Camera } \\
\hline Sensor & $\begin{array}{l}\text { 1'"CMOS } \\
\text { Effective pixels: } 20 \mathrm{M}\end{array}$ \\
\hline Lens & 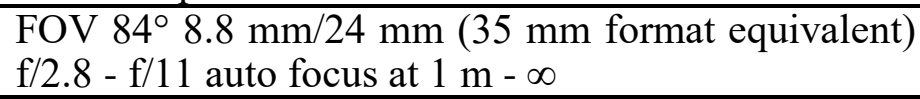 \\
\hline Image & $\begin{array}{l}\text { 3:2 Aspect Ratio: } 5472 \times 3648 \\
\text { 4:3 Aspect Ratio: } 4864 \times 3648 \\
\text { 16:9 Aspect Ratio: } 5472 \times 3078\end{array}$ \\
\hline Photo & JPEG, DNG (RAW), JPEG + DNG \\
\hline Mechanical Shutter Speed & $8-1 / 2000 s$ \\
\hline
\end{tabular}


resolution 170MP camera, 1-million-point data per a second, a measurement error $\pm 2 \mathrm{~mm}$, and a telescope. During each scanning campaign, a single scan station was established at each different location along the hill. The choice of this elementary acquisition scheme was motivated by the need for rapid data acquisition, so that the four areas of interest could be entirely surveyed in less than a working day.

In essence, that laser scanners collect four millions of individual point measurements within 30 minutes. The measurements are then plotted within a single XYZ coordinate system to form a point cloud of the object's external surface (see Fig. 3). Multiple data clouds were collected from different viewpoints can also be combined using common features in order to create one 3D data set. Surveying was purposed to create DEM and relief, which is an important component of any project dealing with the territory (geomorphology, hydrology, land resources etc.).

The surveying was measured with UAV and terrestrial laser scanner, following the instructions in "1:5000 1:2000 1:1000 1:500 topographic mapping". The general workflow for data acquisition and processing is shown in Fig. 4.

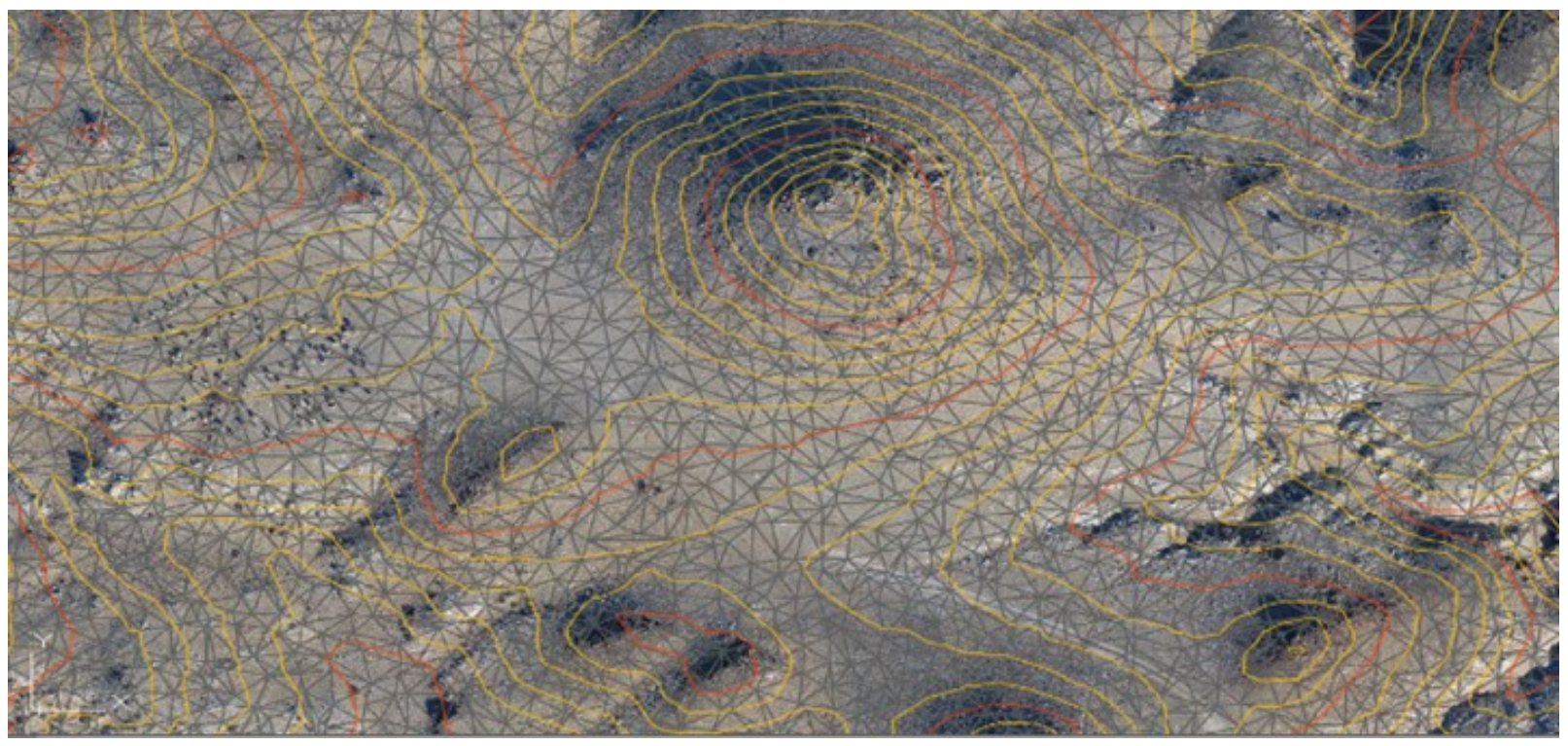

Fig. 2. Orthophoto of the photogrammetric project with contour lines

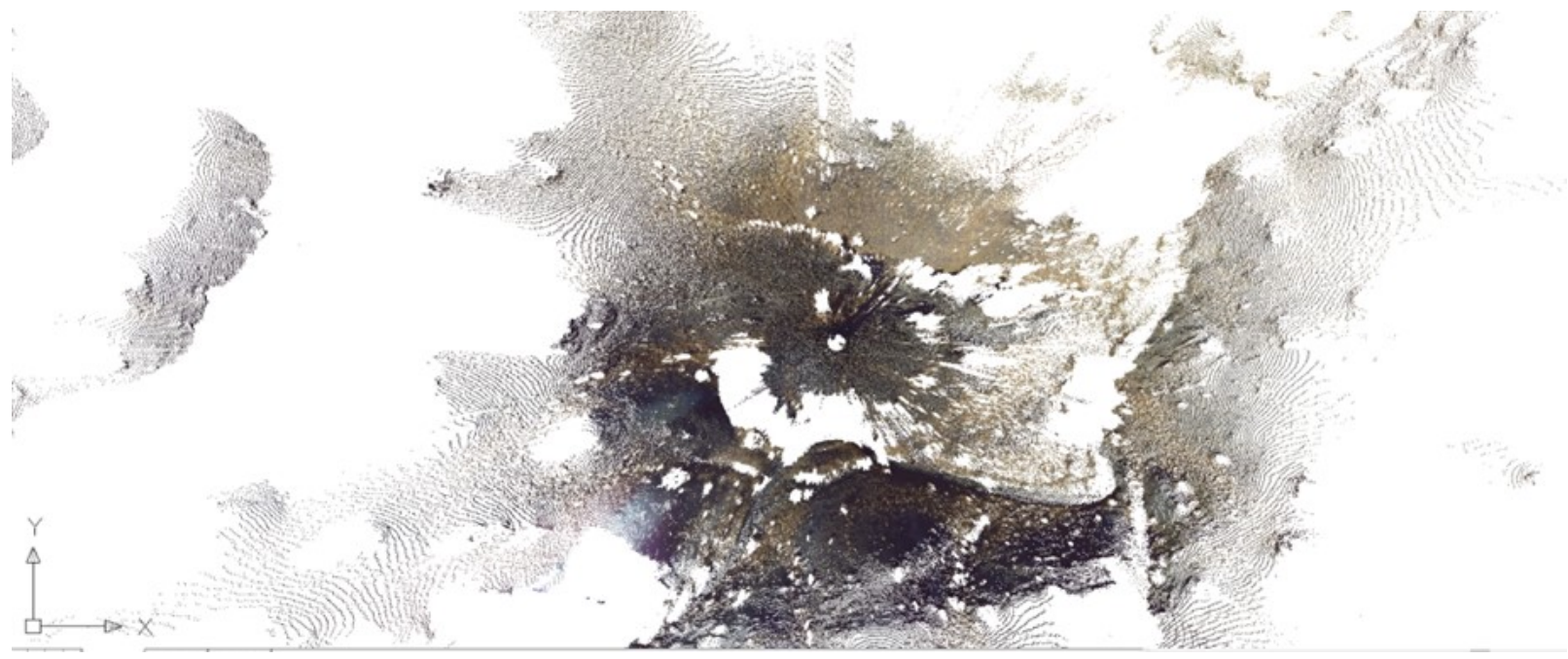

Fig. 3. Point clouds data of surveying with laser scanner 


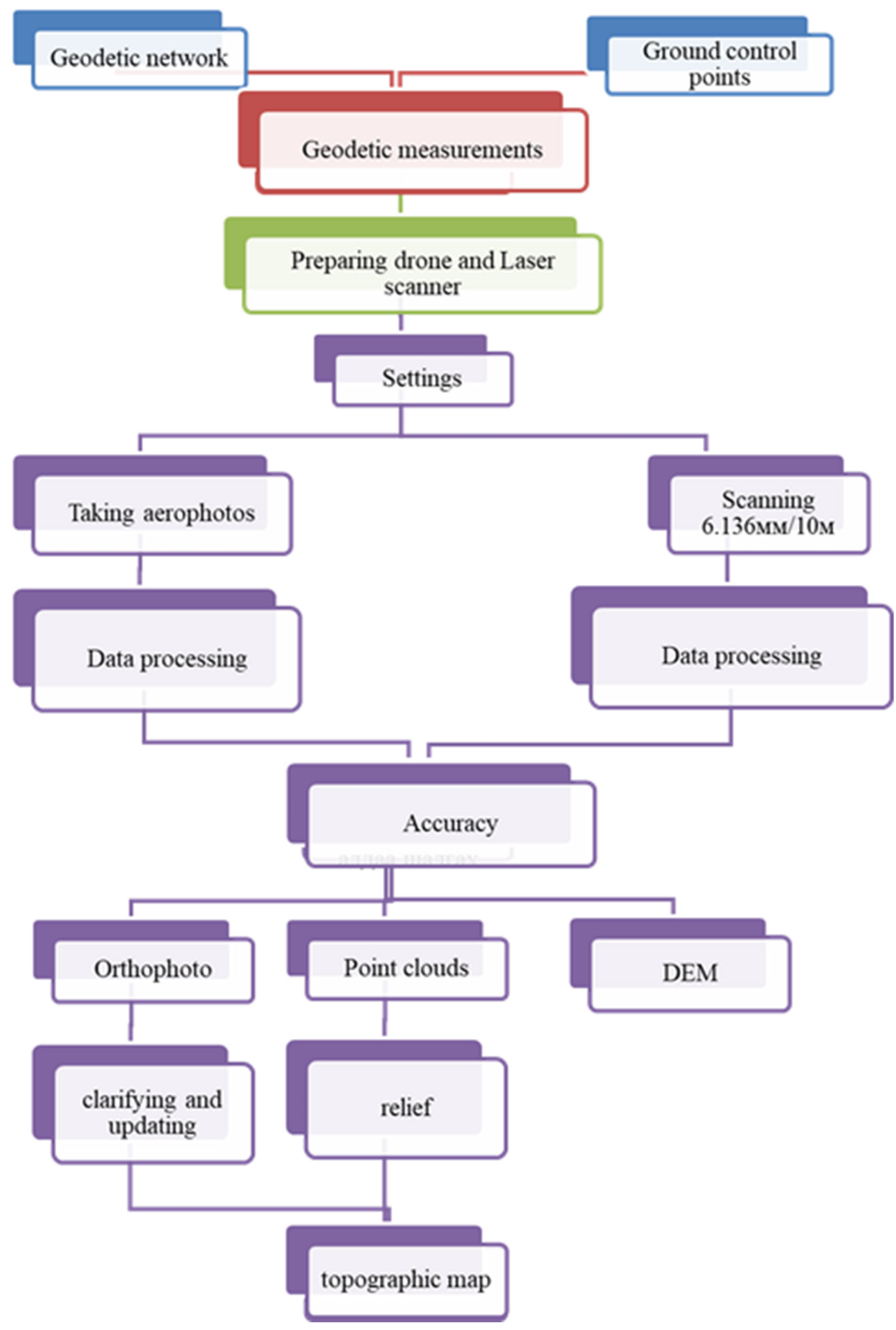

Fig. 4. The general workflow for data acquisition and processing

The products are 1:1000 topographic map and digital data, such as elevation models, orthophotos, 3D models. One means is the digital elevation model, considers the altitude as a continuous variable over the space. The coordinates of the geodetic points of the geodetic network are determined by the method of triangulation. Coordinates and altitudes of triangulation points are as follows.
1. Ehin $X=4873637.118 \mathrm{~m} \mathrm{Y}=685338.737 \mathrm{~m}$ $\mathrm{H}=1305.000 \mathrm{~m}$

2. Asartu $X=4889824.898 \mathrm{~m} Y=686707.766 \mathrm{~m}$ $\mathrm{H}=1387.000 \mathrm{~m}$

3. Buylyus $\mathrm{X}=4889555.106 \mathrm{~m} \mathrm{Y}=705620.488 \mathrm{~m}$ $\mathrm{H}=1276.500 \mathrm{~m}$.

The altitudes and coordinates of ground control points of the geodetic network are determined 


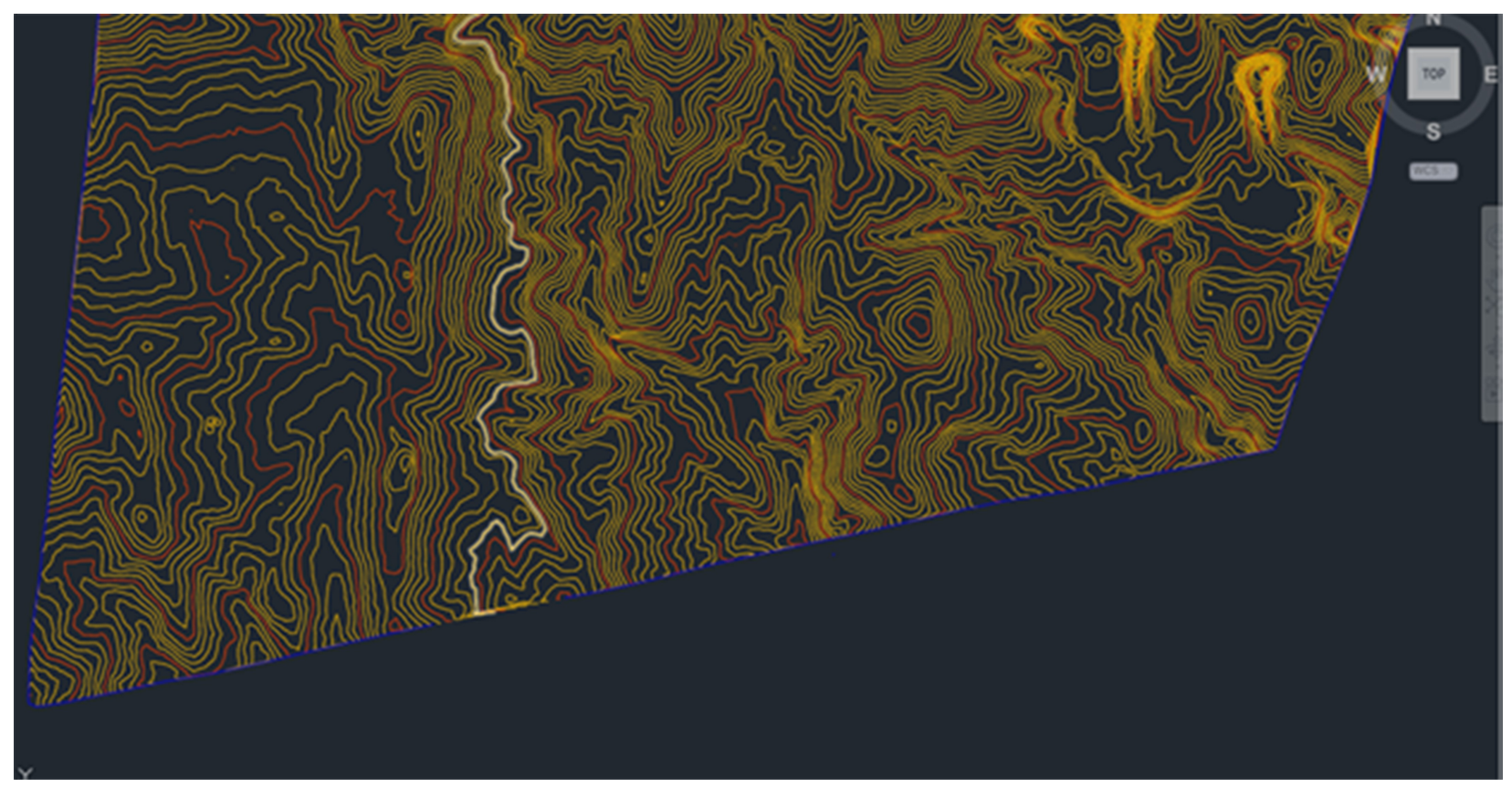

Fig. 5. From point cloud data to minor and major contours using AutoCAD Map

by the methods of GNSS technology. The mean accuracy of the interposition point was established no more than $3 \mathrm{~cm}$ for the position and $5 \mathrm{~cm}$ for the height. Shaded relief of point clouds on AutoCAD Map software is shown Fig. 5.

The DEMs corresponds to a regular grid of elevation. Each node of the grid shows an altitude value. Quality value and geometric data of geomorphology map depend on DEM accuracy. DEM hill-shade data contain hidden landform features, such as pits, peaks, passes, drainage channels and ridges, drainage basins and hills, etc. (Fisher et al., 2004). Created hillshade raster from the DEM is a grayscale $3 \mathrm{D}$ representation of the surface as shown in Fig. 6, with the sun's relative position taken into account for shading the image. The sun's position was calculated on date of June 22, latitude is $43^{\circ} 20^{\prime}$, as follow (Eq.3):

$$
\mathrm{H}_{\mathrm{s}}=90^{\circ}-\varphi \pm 23.5^{\circ}
$$

where, $H_{S}$ - the sun's position, $j$ - latitude

Acquired a $1 \mathrm{~m}$ resolution DEM from UAV was overlapped with orthophotos, which is an aerial photograph corrected to scale such that geodetic measurements may be taken directly from perpendicular point. In result, overlapping orthophoto is provided for geomorphological map (Fig. 7).

A digital orthophoto map is an image obtained by vertical parallel projection of a surface ( $\mathrm{Yu}$ Liu et al., 2018), and has the geometric accuracy of a map and visual characteristics of an image. Therefore, overlapped orthomosaic and topographic map will be used for many various geomorphological topics, surveying and land monitoring researches.

\section{DISCUSSION}

The data sets for two source data collection methods appear very similar in field area. It is important to note that the most prominent concentration of points clouds all data sets resulting from laser scanner measurements.

UAV low-altitude remote sensing has a wide range of applications. It allows for the rapid remote surveying of inaccessible areas, and can be used to monitor active volcanos, geothermally active areas, and open-pit mines (Marsella et al., 2014, Harvey et al., 2016, Tong et al., 2015). Fixed-wing UAV achieve typically a resolution of about $5 \mathrm{~cm}$ per pixel for a flight at about $150 \mathrm{~m}$ height (Campana, 2017) and but for Phantom 4 Pro type of UAV it is about $5 \mathrm{~cm}$ per pixel for a flight at about $180 \mathrm{~m}$ height. Their flight time is generally limited to no more 
than 20 minutes due to battery capacity. The multi-rotor drones have accurate positioning, a good level of automation and a high geometric resolution of data acquisition (Campana, 2017) difference to DJI systems. Used UAV has a max flight time of 30 minutes, and a max transmission range of $4.1 \mathrm{mi}(7 \mathrm{~km})$. In contrast to fixed-wing UAV, they can be used for imaging vertical cliff faces in great detail (Nieminski and Graham, 2017), a critical advantage for carbonate geological field work.
Hence, Phantom 4 Pro UAV could be used to large scale topographic map, geomorphological map such as the Sharga Hill, along to dried-up river etc.

During this survey 200 photos were taken, with a $180 \mathrm{~m}$ mean flight altitude. The computed RMS error is $0.054 \mathrm{~m}$ for geodetic surveying, more which could be considered sufficient for the relative positioning of the points surveyed by the mapping engineers. Fig. 5 shows an elevation interval that follows the calculated

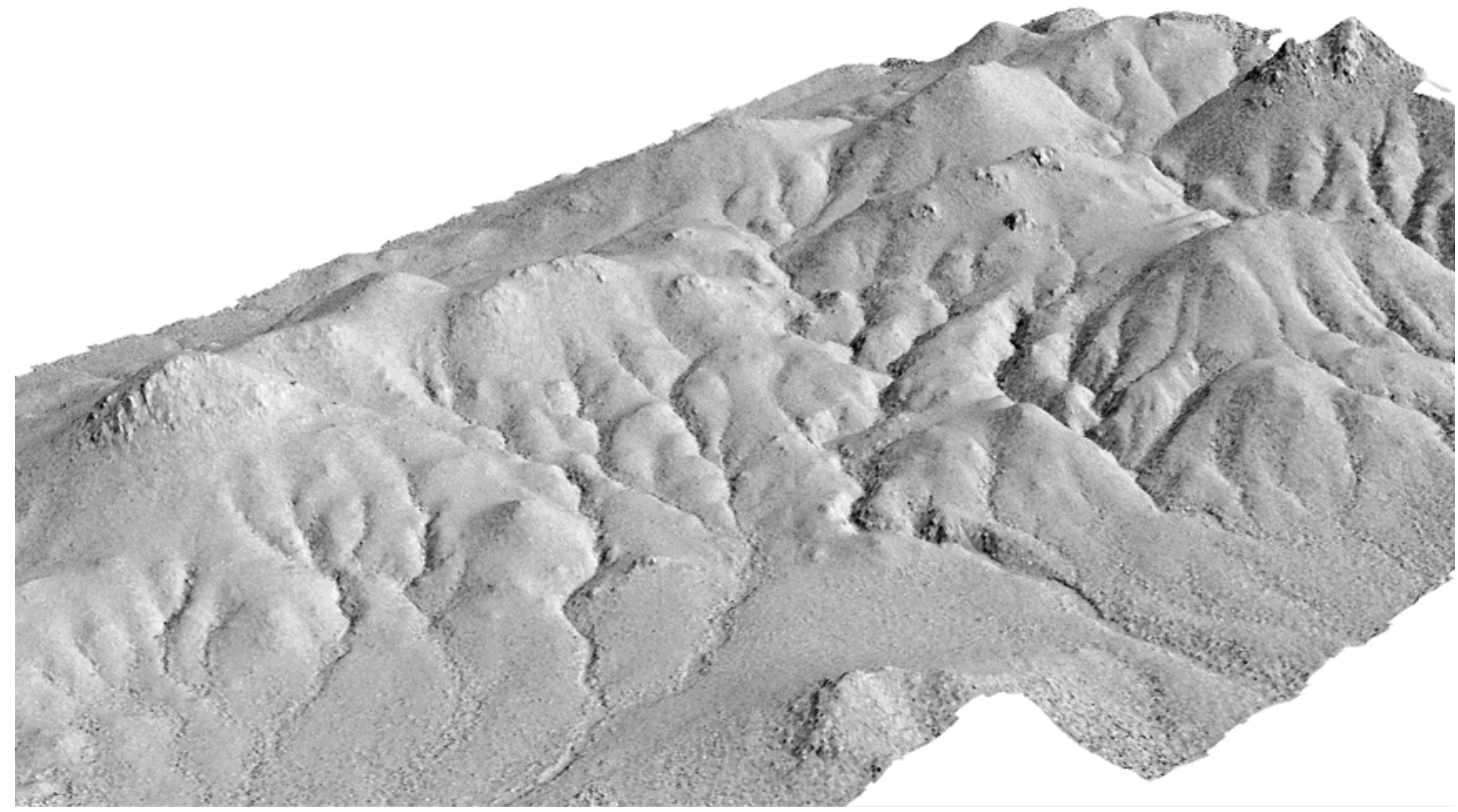

Fig. 6. Created hill shade raster from the DEM

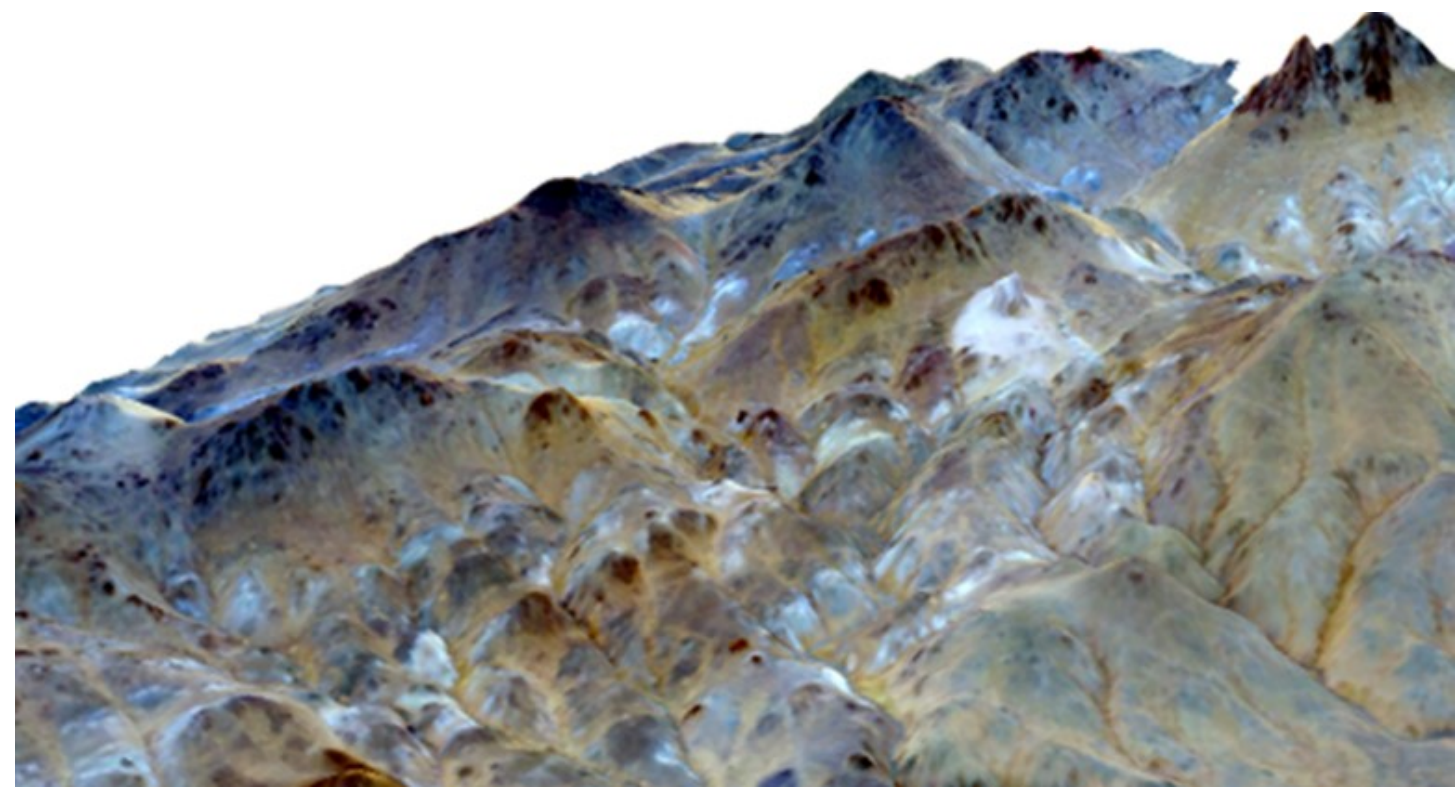

Fig. 7. Overlapping of orthomosaic and DEM 
UTM projection on Derive math software. In Fig. 7, the overlay details, especially in the geomorphology release areas are clearly visible. When using laser scanners, measurements were made to measure the distance between the instrument and objects at a distance of about 50 $\mathrm{m}$, the image format $10240 \times 4267$, the point spacing $6.136 \mathrm{~mm} / 10 \mathrm{~m}$, the resolution $6 \mathrm{x}$, and the duration 32 minutes, and the four stops (spheres) connecting each stop.

In our study, we used equipped with a 1 -inch sensor, the Phantom 4 Pro camera shoots $4 \mathrm{~K}$ $60 \mathrm{fps}$ video and 20MP stills. Advances in active source sensors for high resolution $3 \mathrm{D}$ data collection mainly focus on laser scanning technologies, which measures the distance to a target based on the travel time of reflected light (Bemis et al., 2014, Hodgetts, 2013). Although airborne LiDAR is possible using drones, they are currently expensive, and further developments in these systems are needed to miniaturize them as suitable payloads for lowcost platforms.

Developments in GPS based surveys and subsequently laser scanning methods have greatly improved accuracy, precision, and extent of mapping (Madjid et al., 2018). Laser scanning techniques are, however, still time consuming, expensive, and restricted by environmental and field conditions (visibility, morphology, etc.). The advance of extraordinarily fast, cost-effective and high geometric resolution aerial photogrammetry using UAV is revolutionary compared to the traditional methods. Created a 3D model and DEM, which combines the two techniques, are more efficient for topology, geomorphology. Quantitative measurements of 3D models constructed from drone surveys have greater repeatability than those from outcrops, are collected in only a fraction of the time, and enable volumetric measurements (Chesley et al., 2017). Moreover, using the drones for field surveys is very flexible and practical. The laser scanning technique should be used for hard geodetic field conditions. Depending on the type of land cover data can still be collected by manual survey or by the use of a laser scanning technique.
This combined method could offer many other opportunities for topographic and geomorphological research.

\section{CONCLUSION}

The results were evaluated by RMSE according to the States National Standard for spatial data accuracy. An accuracy of elevation measurements is given $0.0142 \mathrm{~m}$. Positioning accuracy is $0.0441 \mathrm{~m}$. Topographic maps with absolute errors of high accuracy can be achieved with full control GCP from the UAV and laser scanner, providing relatively inexpensive measures in order to generate DEM sufficient enough for large scale topographical mapping requirements in Mongolia.

Calibration of the horizontal cross cylinder is performed on the WGS-84 ellipsoid, m, p (1.001 to 1.002) on the angular and longitudinal shafts of the length and field. That distortion of equal area and equal distant are inherent to the UTM map projection.

For the DEM, it is necessary to implement full control, i.e. more GCPs / model in order to fulfill 1:1.000 topographic mapping accuracy. The topographic map is obtained by dual technology provides high accuracy. In the future, it is considered to be fully applicable to other researchers and geospatial industries.

\section{REFERENCES}

Bayanjargal, B., Nyamkhuu, M. 2017. Methodological issues in processing mediumscale geomorphological map (in Mongolian).

Bemis, S.P., Micklethwaite, S., Turner, D., James, M.R., Akciz, S., Thiele, S.T., Bangash, H.A. 2014. Ground-based and UAV-Based photogrammetry: A multi-scale, highresolution mapping tool for structural geology and paleoseismology. Journal of Structural Geology, v. 69, p. 163-178. https:// doi.org/10.1016/j.jsg.2014.10.007

Blistan, P., Kovanič, L., Zelizňaková, V., Palková, J. 2016. Using UAV photogrammetry to document rock outcrops. Acta Montanistica Slovaca v. 21(2), p. 154161.

Campana, S. 2017. Drones in Archaeology. State-of-the-art and Future Perspectives. 
Archaeological Prospection, v. 24(4), p. 275296. https://doi.org/10.1002/arp.1569

Chesley, J.T., Leier, A.L., White, S., Torres, R. 2017. Using unmanned aerial vehicles and structurefrom-motion photogrammetry to characterize sedimentary outcrops: An example from the Morrison Formation, Utah, USA. Sedimentary Geology, v. 354, p. 1-8. https://doi.org/10.1016/j.sedgeo.2017.03.013

Fisher, P., Wood, J., Cheng, T., 2004. Multiscale morphometry and the mountains of the English lake district. Transactions of the Institute of British Geographers, v. 29(1), p. 106-128. https://doi.org/10.1111/j.00202754.2004.00117.x

Harvey, M.C., Rowland, J.V., Luketina, K.M. 2016. Drone with thermal infrared camera provides high resolution georeferenced imagery of the Waikite geothermal area, New Zealand. Journal of Volcanology and Geothermal Research, v. 325, p. 61-69. https://doi.org/10.1016/ j.jvolgeores.2016.06.014

Hodgetts, D. 2013. Laser scanning and digital outcrop geology in the petroleum industry: A review. Marine and Petroleum Geology, v. 46, p. 335-354. https://doi.org/10.1016/ j.marpetgeo.2013.02.014

Joachim, H. 2017. From classification results to topographic maps, Aalborg University, Department of Development and Planning, Denmark, Generating Topographic Map Data from Classification Results, Remote Sensing, v. 9(3), p. 224. https://doi.org/10.3390/ rs9030224

Liu, Y., Zheng, X., Ai, G., Zhang, Y., Zuo, Y. 2018. Generating a High-Precision True Digital Orthophoto Map Based on UAV Images, ISPRS International Journal of GeoInformation, v. 7(9), p. 333. https:// doi.org/10.3390/ijgi7090333

Madjid, M.Y.A., Vandeginste, V., Hampson, G., Jordan, C.J., Booth, A.D. 2018. Drones in carbonate geology: Opportunities and challenges, and application in diagenetic dolomite geobody mapping, Marine and Petroleum Geology, v. 91, p. 723-734. https:// doi.org/10.1016/j.marpetgeo.2018.02.002

Manchuk, J.G. 2009. Conversion of Latitude and Longitude to UTM Coordinates, Paper
410, CCG Annual Report 11, p. 1-4.

Marsella, M., Nardinocchi, C., Proietti, C., Daga, L., Coltelli, M. 2014. Monitoring Active Volcanos Using Aerial Images and the Orthoview Tool. Remote Sensing, v. 6, p. 12166-12186. $\quad$ https://doi.org/10.3390/ rs61212166

Martínez-Espejo Zaragoza, I., Caroti, G., Piemonte, A., Riedel, B., Tengen, D., Niemeier, W. 2017. Structure from Motion (SfM) Processing of UAV Images and Combination with Terrestrial Laser Scanning, Applied for a 3d-Documentation in a Hazardous Situation. Geomatics, Natural Hazards and Risk, v. 8(2), p. 1492-1504. https://

doi.org/10.1080/19475705.2017.1345796

Neitzel, F., Klonowski, J. 2011. Mobile 3D mapping with a low-cost UAV System. International Archives of the Photogrammetry, Remote Sensing and Spatial Information Sciences, v. XXXVIII-1/C22, p. 39-44. https://doi.org/10.5194/isprsarchivesXXXVIII-1-C22-39-2011

Nieminski, N.M., Graham, S.A., 2017. Modeling stratigraphic architecture using small unmanned aerial vehicles and photogrammetry: examples from the Miocene East Coast Basin, New Zealand. Journal of Sedimentary Research v. 87, p. 126-132. https://doi.org/10.2110/jsr.2017.5

Niethammer, U., James, M.R., Rothmund, S., Travelletti, J., Joswig. M. 2012. UAV-based Remote Sensing of the Super-Sauze Landslide: Evaluation and Results. Engineering Geology v. 128, p. 2-11. https:// doi.org/10.1016/i.enggeo.2011.03.012

Ruiz, J.J., Diaz-Mas, L., Perez, F., Viguria, A. 2013. Evaluating the accuracy of dem generation algorithms from UAV imagery. International Archives of the Photogrammetry, Remote Sensing and Spatial Information Sciences, v. XL-1/W2, p.333337. https://doi.org/10.5194/isprsarchives-XL -1-W2-333-2013

Tampubolon, W., Reinhardt, W. 2014. UAV data processing for large scale topographical mapping, The International Archives of the Photogrammetry, Remote Sensing and Spatial Information Sciences, v. XL-5, p. 565-572. 
https://doi.org/10.5194/isprsarchives-XL-5565-2014

Tong, X., Liu, X., Chen, P., Liu, S., Luan, K., Li, L., Liu, S., Liu, X., Xie, H., Jin, Y., Hong, Z. 2015. Integration of UAV-Based Photogrammetry and Terrestrial Laser Scanning for the Three-Dimensional Mapping and Monitoring of Open-Pit Mine Areas. Remote Sensing, v. 7, p. 6635-6662. https:// doi.org/10.3390/rs 70606635

Uysal, M., Toprak, A.S, Polat, N. 2015. DEM generation with UAV Photogrammetry and accuracy analysis in Sahitler hill, Measurement, v. 73, p. 539-543. https:// doi.org/10.1016/j.measurement.2015.06.010
Vosselman, G., Maas, H.G. 2010. Airborne and Terrestrial Laser Scanning. Boca Raton, CRC Press, $318 \mathrm{p}$.

Xing, C., Wang, J., Xu, Y. 2010. Overlap Analysis of the Images from Unmanned Aerial Vehicles. International Conference on Electrical and Control Engineering, Wuhan, p. 1459-1462. https://doi.org/10.1109/ 